\title{
SPECTROPHOTOMETRIC DETERMINATION OF PIZOTEFIN MALEATE IN PURE FORM AND TABLETS USING $\pi$-ACCEPTORS
}

\author{
Alaa S. Amin ${ }^{1}$, Ayman A. Gouda ${ }^{2 *}$, Ragaa El Sheikh ${ }^{2}$ and Eman H. Youssef ${ }^{1}$ \\ ${ }^{1}$ Chemistry Department, Faculty of Sciences, Benha University, Benha, Egypt \\ ${ }^{2}$ Chemistry Department, Faculty of Sciences, Zagazig University, Zagazig, Egypt
}

(Received September 6, 2014; revised January 7, 2015)

\begin{abstract}
Two simple, quick and sensitive methods were described for the spectrophotometric determination of pizotefin maleate (PZT) either in pure form or pharmaceutical form (tablets). The methods were based on the reaction of pizotefin maleate as ' $\mathrm{n}$ ' electron donor with chloranilic acid ( $p$-CLA) and 7,7,8,8tetracyanoquinodimethane (TCNQ) as $\pi$-acceptors to give highly coloured radical anion species which were quantitated spectrophotometrically at 533 and $839 \mathrm{~nm}$ for chloranilic acid and 7,7,8,8-tetracyanoquinodimethane, respectively. Different experimental conditions for the two methods were optimized. Beer's law was obeyed in the concentration ranges of 10-160 and 2.0-20 $\mathrm{g} \mathrm{mL}^{-1} \mathrm{PZT}$ for $p$-CLA and TCNQ, respectively with good correlation coefficient of $\geq 0.9993$ and a relative standard deviation (RSD) of $\leq 1.31 \%$. The molar absorptivity, Sandell sensitivity, detection and quantification limits were also reported. The proposed methods were successfully applied for determination of PZT in tablets with good accuracy and precision and without interferences from common additives by applying the standard addition technique. The developed methods have been validated statistically for their accuracy, precision, sensitivity, selectivity, robustness and ruggedness as per ICH guidelines and the results compared favourably with those obtained using the reported method.
\end{abstract}

KEY WORDS: Pizotefin maleate, Charge transfer complexes, Spectrophotometry, Tablets

\section{INTRODUCTION}

Pizotifen maleate (PZT) is a sedating antihistamine that has strong serotonin antagonist and weak antimuscarinic properties. It is chemically known as 9,10-dihydro-4-(1-methylpiperidin-4ylidene)-4H-benzo[4,5]cyclohepta[1,2-b]thiophene hydrogen maleate (Figure 1) [1]. It also antagonises the action of tryptamine. Pizotifen is used, usually as the maleate, for the prophylaxis of migraine and for the prevention of headache attacks during cluster periods. It is not effective in treating an acute attack [2]. The drug is official in British Pharmacopoeia [1], which describes a potentiometric titration with perchloric acid in anhydrous acetic acid medium.

Several analytical methods have been reported for the determination of PZT in pure drug, pharmaceutical dosage forms and biological samples using high performance liquid chromatography [3-7], spectrofluorimetry [8] and two spectrophotometric methods [8, 9]. All the above reported methods developed for the determinationof PZT employed complex analytical techniques, complicated, expensive, require careful control of conditions or skilled personnel and are inaccessible to many laboratories. In contrast, visible spectrophotometry is considered as the most convenient analytical technique in most quality control and clinical laboratories. Spectrophotometric methods have several advantages, such as low interference level, good analytical selectivity, and they are easier, less expensive, and less time consuming compared with most of the other methods.

The molecular interactions between electron donors and acceptors are generally associated with the formation of intensely colored charge transfer complexes, which absorb radiation in the visible region [10]. A variety of electron donating compounds have been reported to yield charge-transfer complexes with various $\pi$-acceptors [11-14].

\footnotetext{
*Corresponding author. E-mail: aymangouda77@gmail.com
} 
The aim of the present work was directed to investigate direct, sensitive, simple and precise spectrophotometric methods for determination of PZT as a good n-electron donor via charge transfer complexation with two $\pi$-acceptors: chloranilic acid ( $p$-CLA) and 7,7,8,8tetracyanoquinodimethane (TCNQ) as chromogenic reagents in pure form and its dosage forms (tablets). The reaction conditions of the methods have been established. In addition, the stoichiometric ratio of reactants was determined. No interference was observed in the determination of PZT from common excipients in levels found in dosage forms. These methods are validated by the statistical data.

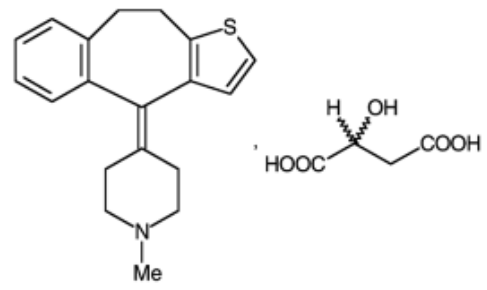

Figure 1. Chemical structure of pizotifen maleate (PZT).

\section{EXPERIMENTAL}

\section{Apparatus}

All the absorption spectra were made using double beam Unikon 930 spectrophotometer (Kontron Instruments, Munchen, Germany) with a scanning speed of $200 \mathrm{~nm} / \mathrm{min}$ and a band width of $2.0 \mathrm{~nm}$, equipped with $10 \mathrm{~mm}$ matched quartz cells.

\section{Materials and reagents}

Pharmaceutical grade pizotefin maleate (PZT) was received from (Novartis, Egypt). Mosegor tablets, labeled to contain $(0.5 \mathrm{mg}$ PZT per tablet) were purchased from local commercial markets.

\section{Standard PZT solution}

A stock standard solution of PZT $\left(500 \mu \mathrm{g} \mathrm{mL}^{-1}\right)$ was prepared by dissolving an exact weight (50 $\mathrm{mg}$ ) of pure PZT in about $10 \mathrm{~mL}$ methanol and the volume was diluted to the mark in a $100 \mathrm{~mL}$ calibrated flask with acetonitrile. Stock solutions of PZT $\left(100 \mu \mathrm{g} \mathrm{mL}^{-1}\right)$ and $\left(5.0 \times 10^{-3} \mathrm{M}\right)$ were prepared from suitable dilution of the stock standard solution. The stock solutions of PZT are stable for a period of 3.0 days when kept in the refrigerator.

\section{Reagents}

All the reagents and chemicals used were of analytical or pharmaceutical grade and all solutions were prepared fresh daily. Chloranilic acid ( $p$-CLA) (Fluka, Switzerland) and 7,7,8,8tetracyanoquinodimethane (TCNQ) (Aldrich Chem. Co., Milwaukee, USA) and stock solution $\left(1.0 \times 10^{-3} \mathrm{M}\right)$ of each reagent were freshly prepared in acetonitrile. The solutions were stable for at least one week at $4{ }^{\circ} \mathrm{C}$ and kept in the dark when not use. 


\section{Recommended procedures}

Two sets of experiments were carried out. In first set, aliquots $(0.2-3.2 \mathrm{~mL})$ of standard PZT $\left(500 \mu \mathrm{g} \mathrm{mL}^{-1}\right)$ solution were accurately transferred into $10-\mathrm{mL}$ calibrated flasks in case of using p-CLA; whereas aliquots of (0.1-1.0 mL) of standard PZT $\left(200 \mu \mathrm{g} \mathrm{mL} \mathrm{mL}^{-1}\right)$ solution were transferred into $10-\mathrm{mL}$ calibrated flasks in the second set in case of using TCNQ; then added to each flask 2.0 and $1.0 \mathrm{~mL}$ of $\left(1.0 \times 10^{-3} \mathrm{M}\right) p$-CLA and TCNQ reagents in the first and second set, respectively. The reaction mixtures were heated in a water-bath at $60 \pm 5^{\circ} \mathrm{C}$ for $10 \mathrm{~min}$. The mixtures were cooled and then diluted to volume up to $10 \mathrm{~mL}$ with acetonitrile and the absorbance was measured at 533 and $839 \mathrm{~nm}$ for $p$-CLA and TCNQ, respectively, against a reagent blanks prepared in the same manner.

\section{Procedure for pharmaceutical formulations (tablets)}

The contents of twenty Mosegor tablets ( $0.5 \mathrm{mg}$ PZT per tablet) were crushed and finely powdered. An accurate weight equivalent to $5.0 \mathrm{mg}$ PZT were transferred into a $100-\mathrm{mL}$ calibrated flask, dissolved in least volume of methanol with shaking for $5.0 \mathrm{~min}$ and filtered through a sintered glass crucible $\left(\mathrm{G}_{4}\right)$ to remove excipient in the powdered tablets. The filtrate was diluted to $25 \mathrm{~mL}$ with acetonitrile in a $25 \mathrm{~mL}$ measuring flask to give $200 \mu \mathrm{g} \mathrm{mL}{ }^{-1}$ stock solution of PZT. For the proposed methods, the content of tablets was calculated using the corresponding regression equation of the appropriate calibration graph. The method of standard addition was used for the accurate determination of PZT contents.

\section{Stoichiometric relationship}

Job's method of continuous variations [15] of equimolar solutions was employed to establish the stoichiometry of the coloured products. Standard solution of PZT $\left(1.0 \times 10^{-3} \mathrm{~mol} \mathrm{~L}^{-1}\right)$ and $(1.0 \mathrm{x}$ $10^{-3} \mathrm{~mol} \mathrm{~L}^{-1}$ ) solution of $p$-CLA or TCNQ were prepared. A series of solutions was prepared in which the total volume of PZT and reagent was kept constant $(2.0 \mathrm{~mL})$. The solutions were mixed in various proportions and the volume was diluted in a $10-\mathrm{mL}$ volumetric flask with acetonitrile. The absorbance of the resulting solutions was measured at optimum wavelengths $\left(\lambda_{\max }\right)$ at best time and temperature against the reagent blank under the same conditions.

\section{RESULTS AND DISCUSSION}

This is the first report on the application of charge-transfer complexation reaction for spectrophotometric determination of PZT in pure form and tablets. The methods are based on well-characterized charge-transfer complex formation of PZT as electron-donor with selected $\pi$ acceptors ( $p$-CLA or TCNQ) in acetonitrile and have the advantages of simplicity, rapid, accuracy and precision, and use of inexpensive equipment compared to the reported HPLC methods.

\section{Absorption spectra}

The reaction of $p$-CLA and TCNQ as a $\pi$-acceptor with PZT as n-electron donor results in the formation of an intense orange-red and bluish-green colored radical anions ( $p$-CLA ${ }^{-}$and $\mathrm{TCNQ}^{-}$) in acetonitrile, which exhibits strong absorption maxima at wavelengths 533 and 839 $\mathrm{nm}$, respectively (Figures 2 and 3), most probably due to the formation of charge-transfer complexes between PZT acting as n-donor (D) or Lewis base, and $p$-CLA or TCNQ, as $\pi$ acceptors(A) or Lewis acids [10]: 


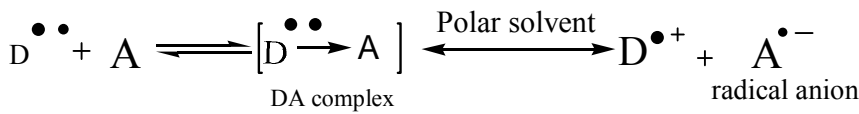

The dissociation of DA complex is promoted by the high dielectric constant of acetonitrile (37.5). Further support for the assignment was provided by the comparison of the absorption bands with those of the $p$-CLA ${ }^{-}$and $\mathrm{TCNQ}^{-}$radical anions produced by the iodide reduction method [16].

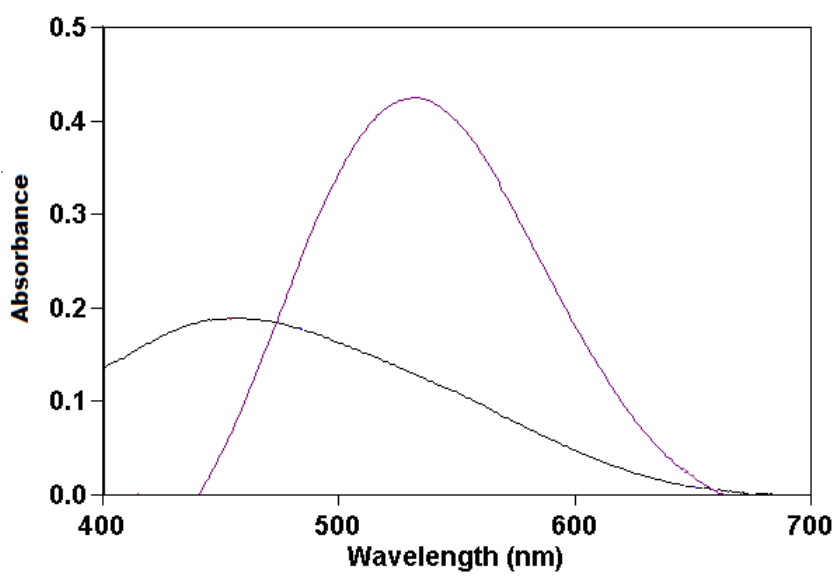

Figure 2. Absorption spectra of reaction products of $160 \mu \mathrm{g} \mathrm{mL} \mathrm{m}^{-1}$ PZT with $p$-CLA $\left(1.0 \times 10^{-3}\right.$ $\mathrm{M})$ against blank solution.

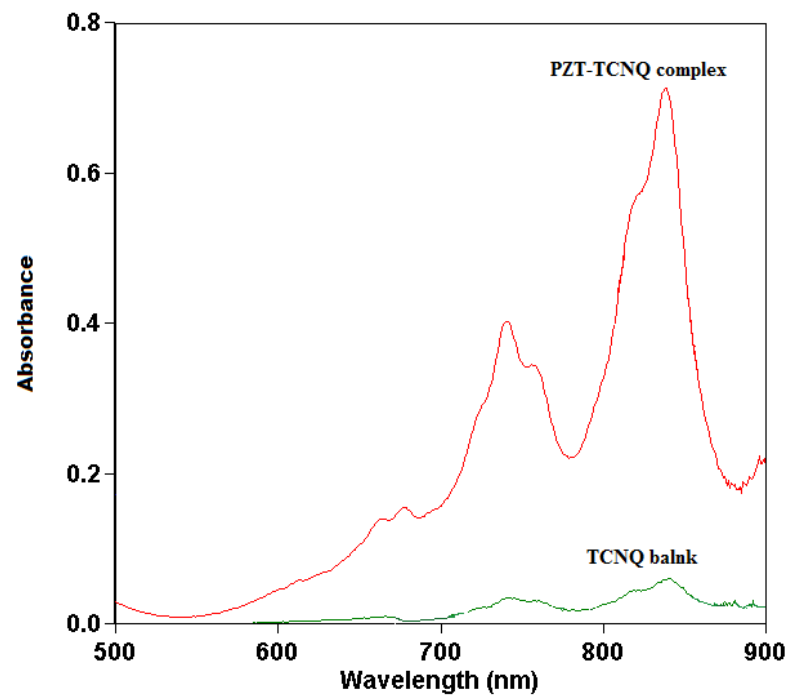

Figure 3. Absorption spectra of reaction products of $30 \mu \mathrm{g} \mathrm{mL}{ }^{-1}$ PZT with TCNQ $\left(1.0 \times 10^{-3} \mathrm{M}\right)$ against blank solution.

Bull. Chem. Soc. Ethiop. 2015, 29(2) 
Optimization of reaction conditions

\section{Effect of solvents}

In order to select the suitable solvent for charge transfer complex formation, the reaction of PZT with $p$-CLA and TCNQ was carried out in different solvents such as acetone, methanol, ethanol, dichloromethane, 1,2-dichloroethane, acetonitrile and chloroform. Acetonitrile was found to be an ideal solvent for all the reagents, because it afforded the maximum sensitivity when compared with all other solvents and it possesses the highest dielectric constant of all solvents examined, a property which is known to promote the dissociation of the original charge-transfer complexes to the CLA" ${ }^{--}$and TCNQ"- radical anions (Figure 4).

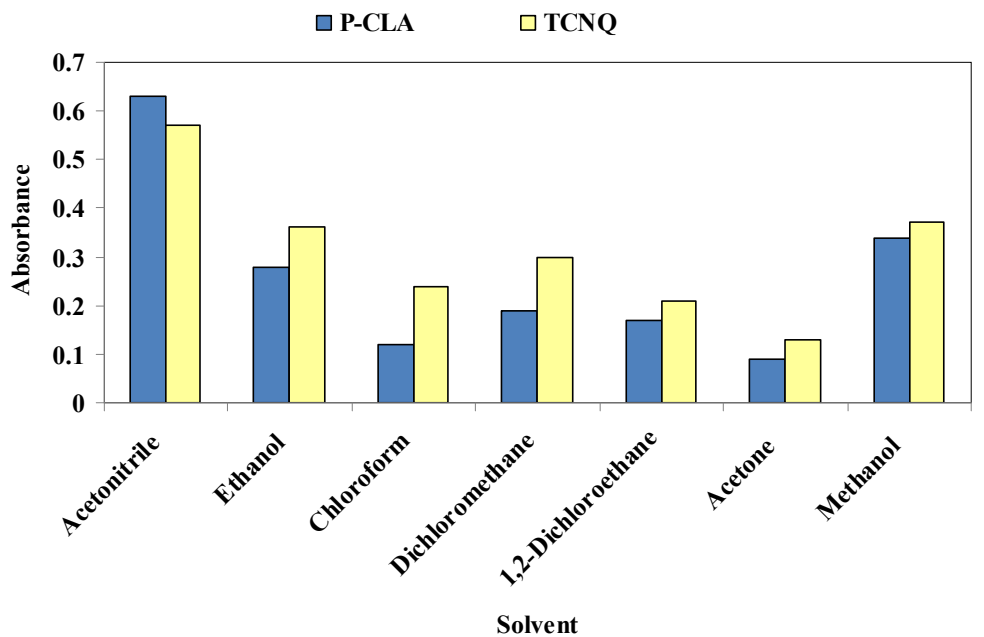

Figure 4. Effect of solvent on the absorbance of charge transfer complex of PZT with $p$-CLA and TCNQ acceptors.

\section{Effect of reagent concentration}

The effect of the reagent concentration on the intensity of the color developed at the selected wavelengths was ascertained by adding different volumes of $p$-CLA and TCNQ reagents to fixed concentrations of PZT. It was found that 2.0 and $1.0 \mathrm{~mL}$ of $\left(1.0 \times 10^{-3} \mathrm{M}\right) p$-CLA and TCNQ solution, respectively, were sufficient for the production of maximum and reproducible color intensity and the highest absorbance remained unaffected by further addition of both reagents (Figure 5).

\section{Effect of ruction time and temperature}

The optimum reaction time was determined by following the colour development at room temperature $\left(25 \pm 2{ }^{\circ} \mathrm{C}\right)$. Complete colour development was attained after $10 \mathrm{~min}$ on raising the temperature on a water-bath to $60 \pm 5{ }^{\circ} \mathrm{C}$ using both $p$-CLA and TCNQ methods. The absorbance of these radical anions remained stable for at least $4.0 \mathrm{~h}$ for $p$-CLA and TCNQ methods. 


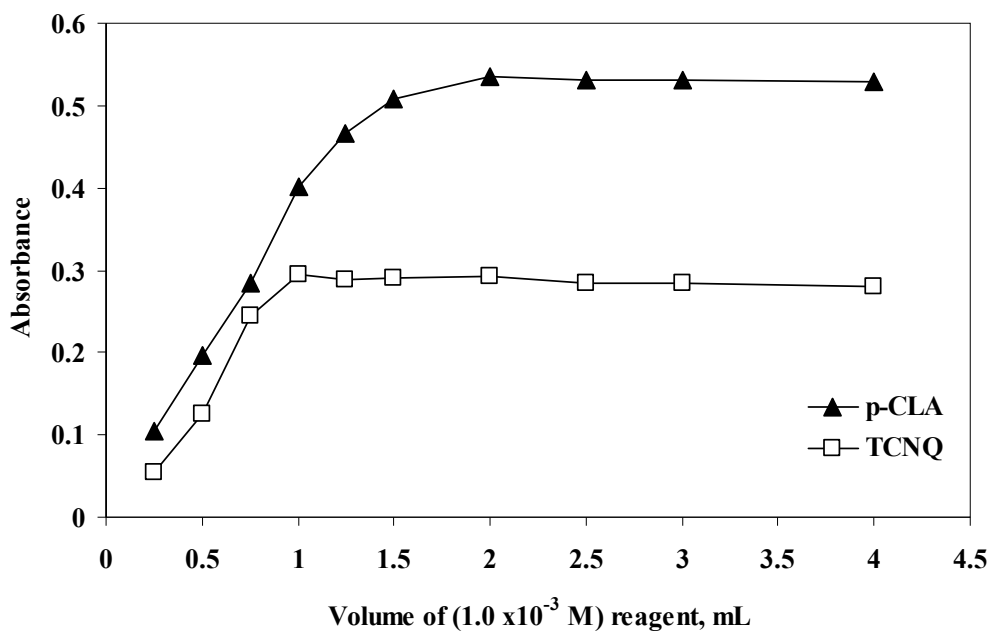

Figure 5. Effect of reagent concentration on the absorbance of charge transfer complexes formed between PZT and $\left(1.0 \times 10^{-3} \mathrm{M}\right) p$-CLA and TCNQ acceptors.

Molar ratio of the reaction

The stoichiometric ratio was determined by Job's method [15] of continuous variation for the reaction between PZT and $p$-CLA and TCNQ reagents, which shows that the interaction occurs between an equimolar solution of the PZT and the reagents. The result indicated that the charge transfer complex was formed in the ratio of 1:1 (Figure 6). On the basis of the literature data and our experimental results, tentative reaction mechanisms for PZT-TCNQ complex is proposed and given in Scheme 1.
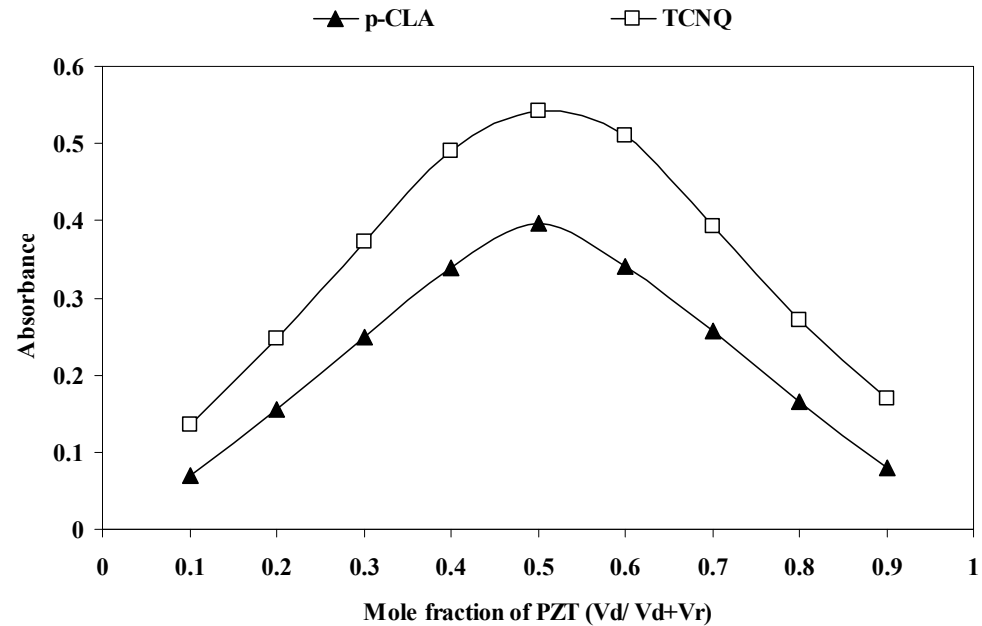

Figure 6. Continuous variation plots for the reaction of PZT with $p$-CLA and TCNQ. $\Lambda=533$ and $839 \mathrm{~nm}$, respectively. Total molar concentration $=1.0 \times 10^{-4} \mathrm{~mol} \mathrm{~L}^{-1}$. 
<smiles>CN1CCC(=C2c3ccccc3CCc3sccc32)CC1</smiles>

PZT
$+$<smiles>N#CC(C#N)=c1ccc(=C(C#N)C#N)cc1</smiles>

TCNQ



PZT-TCNQ complex

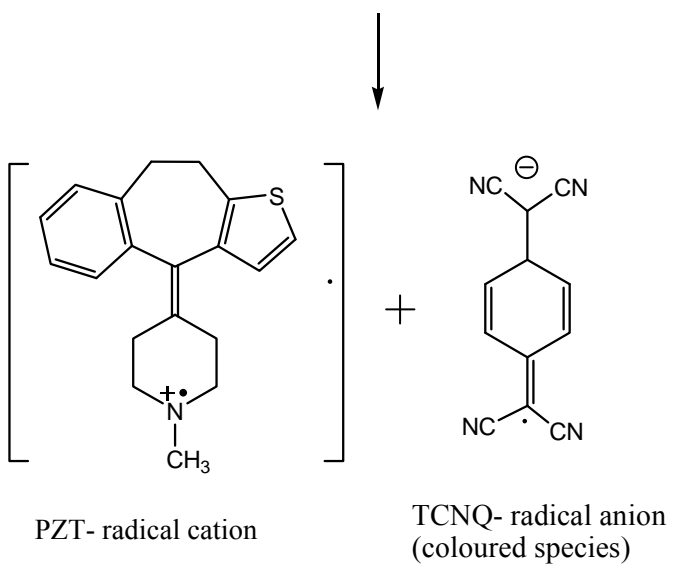

Scheme 1. Proposed reaction pathway for the formation of charge transfer complex between PZT and TCNQ.

\section{Method validation}

Validation of the described methods for assay of bulk PZT was examined via linearity, sensitivity, precision, accuracy, repeatability, reproducibility, selectivity and robustness according to ICH guidelines [17].

\section{Linearity}

Under the optimum conditions a linear correlation was found between absorbance at $\lambda_{\max }$ and concentration of PZT in the ranges of $10-160 \mu \mathrm{g} \mathrm{mL} \mathrm{m}^{-1}$ and $2.0-20 \mu \mathrm{g} \mathrm{mL} L^{-1}$ using $p$-CLA and TCNQ method, respectively. The calibration graph is described by the regression equation:

$$
\mathrm{A}=\mathrm{a}+\mathrm{b} \mathrm{C}
$$

(where $\mathrm{A}=$ absorbance, $\mathrm{a}=$ intercept, $\mathrm{b}=$ slope and $\mathrm{C}=$ concentration in $\mu \mathrm{g} \mathrm{mL}^{-1}$ ) obtained by the method of least squares [18]. Correlation coefficient, intercept and slope for the calibration data are summarized in Table 1. For accurate determination, Ringbom concentration range [19] was calculated by plotting log concentration of drug in $\mu \mathrm{g} \mathrm{mL}^{-1}$ against transmittance $\%$ from which the linear portion of the curve gives accurate range of micro determination of PZT and 
represented in Table 1. The linearity of the calibration graphs was demonstrated by the high values of the correlation coefficient (r) and the small values of the y-intercepts of the regression equations.

Sensitivity parameters such as apparent molar absorptivity $(\varepsilon)$ and Sandell's sensitivity (Ss) values, the limits of detection and quantification were calculated as per the current ICH guidelines (ICH) [17], are illustrated in Table 1. The high molar absorptivity and lower Sandell sensitivity values reflect the good and high sensitivity of the proposed methods. The validity of the proposed methods was evaluated by statistical analysis [20] between the results achieved from the proposed methods and that of the reported methods. Regarding the calculated Student's $t$-test and variance ratio $F$-test (Table 1 ), there is no significant difference between the proposed and reported method [8] regarding accuracy and precision.

Table 1. Analytical and regression parameters of proposed oxidation spectrophotometric methods for determination of PZT.

\begin{tabular}{|l|c|c|}
\hline Parameters & $p$-CLA & TCNQ \\
\hline Wavelengths $\lambda_{\max }(\mathrm{nm})$ & 533 & 839 \\
\hline Color stability & 4.0 & 3.0 \\
\hline Beer's law limits $\left(\mu \mathrm{g} \mathrm{mL}^{-1}\right)$ & $10-160$ & $2.0-20$ \\
\hline Ringbom optimum concentration range $\left(\mu \mathrm{g} \mathrm{mL}^{-1}\right)$ & $20-140$ & $4.0-18$ \\
\hline Molar absorptivity $\varepsilon,\left(\mathrm{L} / \mathrm{mol}^{-1} \mathrm{~cm}^{-1}\right) \times 10^{4}$ & 0.1044 & 0.6145 \\
\hline Sandell's sensitivity $\left(\mathrm{ng} \mathrm{cm}^{-2}\right)$ & 282.95 & 48.07 \\
\hline Regression equation & & \\
\hline Slope $(\mathrm{b})$ & 0.0037 & 0.0199 \\
\hline Intercept $(\mathrm{a})$ & -0.0033 & 0.0033 \\
\hline Correlation coefficient $(r)$ & 0.9993 & 0.9994 \\
\hline Mean $\pm \mathrm{SD}$ & $100.20 \pm 1.31$ & $99.40 \pm 0.96$ \\
\hline Relative standard deviation, RSD\% & 1.31 & 0.96 \\
\hline Relative error, RE\% & 1.37 & 1.01 \\
\hline LOD, $(\mu \mathrm{g} \mathrm{mL})^{-1}$ & 2.83 & 0.54 \\
\hline LOQ,$\left.(\mu \mathrm{g} \mathrm{mL})^{-1}\right)^{\mathrm{b}}$ & 9.43 & 1.80 \\
\hline Calculated $t$-value & 0.75 & 0.47 \\
\hline Calculated $F$-value & \\
\hline
\end{tabular}

${ }^{\mathrm{a}} A=a+b C$, where $C$ is the concentration in $\mu \mathrm{g} \mathrm{mL}{ }^{-1}, A$ is the absorbance units, $a$ is the intercept, $b$ is the slope. ${ }^{\mathrm{b}} \mathrm{LOD}$, limit of detection; LOQ, limit of quantification; $\varepsilon$, molar absorptivity. ${ }^{\mathrm{c}}$ The theoretical values of $t$ and $F$ are 2.57 and 5.05 , respectively at confidence limit at $95 \%$ confidence level and five degrees of freedom $(p=0.05)$.

\section{Sensitivity}

The limit of detection (LOD) is defined as the minimum level at which the analyte can be reliably detected for the drug was calculated using the following equation [17] and listed in Table 1: $\mathrm{LOD}=3.3 \sigma / S$, where $\sigma$ is the standard deviation of replicate determination values under the same conditions as for the sample analysis in the absence of the analyte and $S$ is the slope of the calibration graph. In accordance with the formula, the limits of detection were found to be 2.83 and $0.54 \mu \mathrm{g} \mathrm{mL}^{-1}$ using $p$-CLA and TCNQ, respectively. The limits of quantification, LOQ, is defined as the lowest concentration that can be measured with acceptable accuracy and precision [17], $\mathrm{LOQ}=10 \sigma / \mathrm{S}$. According to this equation, the limit of quantification was found to be 9.43 and $1.80 \mu \mathrm{g} \mathrm{mL}^{-1}$ using $p$-CLA and TCNQ, respectively.

\section{Accuracy and precision}

The accuracy and precision of the proposed methods (within-day and between-days) were evaluated by performing six replicate analyses on pure drug solution at three different 
concentrations of PZT (within the working range). Percentage relative standard deviation (\% RSD) as precision and percentage relative error (\% RE) as accuracy of the proposed spectrophotometric methods were calculated. The relative standard deviation (RSD) values were $\leq 1.1 \%$ in all cases, indicating good repeatability of the suggested methods. This level of precision of the proposed methods was adequate for the quality control analysis of the studied drugs. \% RE, an indicator of accuracy, is in the range (-0.7-0.6) also indicating high accuracy and repeatability of the methods. The intra-day and inter-day precision and accuracy results show that the proposed methods have good repeatability and reproducibility reflecting the usefulness of the methods in routine analysis (Table 2).

Table 2. Evaluation of intra-day and inter-day accuracy and precision for PZT obtained by the proposed methods.

\begin{tabular}{|c|c|c|c|c|c|}
\hline Methods & $\begin{array}{c}\text { Added } \\
\left(\mu \mathrm{g} \mathrm{mL}^{-1}\right)\end{array}$ & $\begin{array}{c}\text { Recovery } \\
\%\end{array}$ & $\begin{array}{l}\text { Precision } \\
\text { RSD \% }\end{array}$ & $\begin{array}{c}\text { Accuracy } \\
\text { RE } \%\end{array}$ & Confidence limit $^{\mathrm{b}}$ \\
\hline & \multicolumn{5}{|c|}{ Intra-day } \\
\hline \multirow[t]{3}{*}{$p$-CLA } & 40 & 99.6 & 0.57 & -0.40 & $39.8 \pm 0.24$ \\
\hline & 80 & 99.9 & 0.91 & -0.10 & $79.9 \pm 0.76$ \\
\hline & 160 & 99.3 & 1.08 & -0.70 & $159 \pm 1.80$ \\
\hline \multirow[t]{4}{*}{ TCNQ } & 5.0 & 99.4 & 0.64 & -0.65 & $4.97 \pm 0.01$ \\
\hline & 10 & 100 & 0.86 & 0.25 & $10.0 \pm 0.08$ \\
\hline & 15 & 99.9 & 1.07 & -0.10 & $15.0 \pm 0.15$ \\
\hline & \multicolumn{5}{|c|}{ Inter-day } \\
\hline \multirow[t]{6}{*}{$p$-CLA } & 40 & 99.7 & 0.48 & -0.30 & $39.9 \pm 0.20$ \\
\hline & 80 & 100 & 0.85 & 0.10 & $80.1 \pm 0.71$ \\
\hline & 160 & 101 & 0.99 & 0.60 & $161 \pm 1.67$ \\
\hline & 5.0 & 99.8 & 0.54 & -0.20 & $4.99 \pm 0.03$ \\
\hline & 10 & 99.5 & 0.70 & -0.55 & $9.95 \pm 0.07$ \\
\hline & 15 & 100 & 0.96 & 0.35 & $15.1 \pm 0.14$ \\
\hline
\end{tabular}

${ }^{\mathrm{a}}$ Mean of six determination, RSD\%, percentage relative standard deviation; RE\%, percentage relative error. ${ }^{\mathrm{b}} \mathrm{Mean}$ \pm standard error.

\section{Robustness and ruggedness}

The robustness of the methods was evaluated by making small incremental changes in the volume of reagent $( \pm 0.2 \mathrm{~mL})$ and time $( \pm 1.0 \mathrm{~min})$, and the effect of the changes were studied on the absorbance of the charge transfer complex. The changes had negligible influence on the results as revealed by small intermediate precision values expressed as $\mathrm{RSD} \%(\leq 2.60 \%)$. Method ruggedness was demonstrated having the analysis done by three analysts, and also by a single analyst performing analysis using three different spectrophotometer instruments in the same laboratory. Intermediate precision values $(\mathrm{RSD} \%)$ in both instances were $(\leq 2.0 \%)$ indicating acceptable ruggedness.

\section{Recovery studies by standard addition technique}

The accuracy and validity of the proposed methods were further ascertained by performing recovery studies. In this study, pre-analyzed tablet powder was spiked with pure PZT at different concentration levels and the total was determined by the proposed methods using standard addition technique. The percent recovery of pure PZT added was in the range 98.5$101 \%$ with relative standard deviation of $0.65-0.74$ (Table 3 ) indicating that the recovery was good, and revealed that the co-formulated substances did not interfere in the determination. The results of recovery study are compiled in Table 3. 
Table 3. Application of the standard addition technique for the determination of PZT in Mosegor tablets using the proposed methods.

\begin{tabular}{|c|c|c|c|c|c|c|}
\hline \multirow[t]{2}{*}{ Sample } & \multirow{2}{*}{$\begin{array}{c}\text { Taken } \\
\left(\mu \mathrm{g} \mathrm{mL}^{-1}\right)\end{array}$} & \multicolumn{2}{|c|}{$p$-CLA } & \multirow{2}{*}{$\begin{array}{c}\text { Taken } \\
\left(\mu \mathrm{g} \mathrm{mL}^{-1}\right)\end{array}$} & \multicolumn{2}{|c|}{ TCNQ } \\
\hline & & $\begin{array}{c}\text { Added } \\
\left(\mu \mathrm{g} \mathrm{mL} L^{-1}\right)\end{array}$ & $\begin{array}{c}\text { Recovery }^{\mathrm{a}} \\
(\%)\end{array}$ & & $\begin{array}{c}\text { Added } \\
\left(\mu \mathrm{mL}^{-1}\right)\end{array}$ & $\begin{array}{c}\text { Recovery }^{\mathrm{a}} \\
(\%)\end{array}$ \\
\hline \multirow{6}{*}{$\begin{array}{l}\text { Mosegor } \\
\text { tablets }\end{array}$} & \multirow[t]{6}{*}{10} & - & 99.5 & \multirow[t]{6}{*}{2.0} & - & 99.1 \\
\hline & & 10 & 99.1 & & 2.0 & 99.5 \\
\hline & & 30 & 99.0 & & 4.0 & 99.8 \\
\hline & & 50 & 98.5 & & 8.0 & 99.7 \\
\hline & & 100 & 99.5 & & 12 & 101 \\
\hline & & 150 & 101 & & 16 & 98.6 \\
\hline Mean \pm SD & & & $99.4 \pm 0.7$ & & & $99.5 \pm 0.7$ \\
\hline RSD $\%$ & & & 0.75 & & & 0.65 \\
\hline $\mathrm{V}$ & & & 0.55 & & & 0.42 \\
\hline $\mathrm{SE}$ & & & 0.30 & & & 0.26 \\
\hline
\end{tabular}

${ }^{a}$ Average of six determinations.

\section{Selectivity}

The studied drug (PZT) was determined in the presence of possible excipients and additives such as lactose, microcrystalline cellulose, sodium starch glycolate and magnesium stearate. Under the experimental conditions employed, to a known amount of drug, excipients in different concentrations were added and studied. Excipients do not interfere with the assay indicating the high selectivity of the proposed methods and applicability to use for routine determination in pure and in dosage forms. In addition, recoveries in most cases were around $100 \%$ and the lower values of the RSD $(\leq 2.0 \%)$ indicate the good precision of the methods.

\section{Application of the proposed methods to analysis of tablets}

In order to evaluate the analytical applicability of the proposed methods to the quantification of PZT in commercial tablets, the results obtained by the proposed methods were compared with those of the reference method [8] by means of Student's $t$-test and $F$-test for accuracy and precision. The results (Table 4 ) show that the Student's $t$ - and $F$-values at 95\% confidence level are less than the theoretical values, indicating that there is a good agreement between the results obtained by the proposed methods and the reference method with respect to accuracy and precision.

Table 4. Application of the proposed methods for the determination of PZT in Mosegor tablets using the proposed charge transfer methods.

\begin{tabular}{|c|c|c|c|}
\hline \multirow{2}{*}{ Samples } & \multicolumn{2}{|c|}{ Proposed methods } & \multirow{2}{*}{ Reported method [8] } \\
\cline { 2 - 3 } & $p$-CLA & TCNQ & \\
\hline${\text { Recovery } \pm \text { RSD }^{\mathrm{a}}}^{\mathrm{b}}$ & $99.4 \pm 0.7$ & $99.5 \pm 0.7$ & $99.3 \pm 0.9$ \\
\hline$F$-value & 0.15 & 0.46 & \\
\hline$F$-value & 1.51 & 1.96 & \\
\hline
\end{tabular}

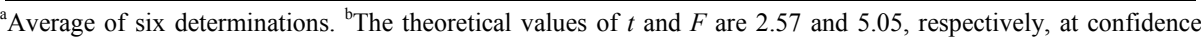
limit at $95 \%$ confidence level and five degrees of freedom $(p=0.05)$.

\section{CONCLUSION}

The present study describes the first report on the application of charge-transfer complexation reaction for spectrophotometric determination of PZT in pure form and tablets using two $\pi$ 
acceptors ( $p$-CLA and TCNQ) as analytical reagents and validated as per the current ICH guidelines. The present spectrophotometric methods are characterized by simplicity since they do not involve any critical experimental variable and are free from tedious, time-consuming, extraction steps and do not need expensive sophisticated apparatus unlike many previous methods. The proposed methods have additional advantages of accuracy, precision, ease of operation and possibility of carrying them out with a common laboratory instrument unlike many other instrumental methods reported for PZT. The methods are characterized by high selectivity and comparable sensitivity with respect to the existing methods. The highlight of the proposed methods is their ability to quantify PZT in tablets. Thus, the methods are useful for the quality control and routine analysis of PZT in pharmaceuticals since there is no interference from the common excipients that might be found in commercial formulations.

\section{REFERENCES}

1. British Pharmacopoeia Monographs: Medicinal and Pharmaceutical Substances, Pizitifen malate, Volume I and II, British Pharmacopoeia Commission Office: London, UK; 2009.

2. Sean, C.S. Martindale, The Complete Drug Reference, 36th ed., Electronic Version, Pharmaceutical Press: Royal Pharmaceutical Society, London; 2009.

3. Serna-Jiménez, C.E.; del Rio Sancho, S.; Calatayud-Pascual, M.A.; Balaguer-Fernández, C.; Femenía-Font, A.; López-Castellano, A.; Merino, V. Biomed. Chromatogr. 2012, 26, 769.

4. Rahman, S.M.; Kabir, A.K.L.; Jahan, A.; Momen, A.R.; Rouf, A.S.S. Pak. J. Pharm. Sci. 2010, 23, 435 .

5. Abounassif, M.A.; El-Obeid, H.A.; Gadkariem, E.A. J. Pharm. Biomed. Anal. 2005, 36, 1011.

6. Basaveswara Rao, M.V.; Nagendrakumar, A.V.D.; Maiti, S.; Chandrasekhar, N. Chromatogr. Res. Int. 2012, 2012, 1.

7. Stout, T.H.; Dorsey, J.G. High-Performance Liquid Chromatography in Hand Book of Pharmaceutical Analysis, Ohannesian, L.; Streeter, A.J. (Eds.), Marcel Dekker, Inc.: New York; 2001; p 138.

8. Dessouky, Y.M.; Hassanein, H.H.; Mohammad, M.A.A.; Hanafy, R.S. Bull. Fac. Pharm. Cairo. Univ. 2004, 42, 41.

8. El-Kousy, N.; Bebawy, L.I. J. Pharm. Biomed. Anal. 1999, 20, 671.

10. Foster, R. Organic Charge Transfer Complexes, Academic Press: London; 1969; p 51.

11. Gouda, A.A.; EL-Sheikh, R.; Amin, A.S. Chem. Pharm. Bull. 2008, 56, 34.

12. Gouda, A.A. Talanta 2009, 80, 151.

13. Gouda, A.A.; EL-Sheikh, R.; El Azzazy, R.M. J. Anal. Bioanal. Techn. 2012, 3, 1.

14. Gouda, A.A.; Amin, A.S.; Youssef, E.H. Int. J. Pharmacy Pharm. Sci. 2014, 6, 154.

15. Job, P. Ann. Chem. 1936, 16, 97, in Advanced Physicochemical Experiments, 2nd ed., Oliner and Boyd: Edinburgh, UK; 1964; p 54.

16. Melby, L.R.; Harder, R.J.; Hertler, W.R.; Mahler, W.; Benson, R.E. J. Am. Chem. Soc. 1962, $84,3374$.

17. International Conference on Harmonisation of Technical Requirements for Registration of Pharmaceuticals for Human Use, ICH Harmonised Tripartite Guideline, Validation of Analytical Procedures: Text and Methodology Q2(R 1), Complementary Guideline on Methodology, London; November 2005.

18. Mendham, J.; Denney, R.C.; Barnes, J.D.; Thomas, M. Vogel's Textbook of Quantitative Chemical Analysis, Pearson Education Ltd: England; 2000.

19. Ringbom, A. Z. Anal. Chem. 1939, 115, 332.

20. Miller, J.N.; Miller, J.C. Statistics and Chemometrics for Analytical Chemistry, 5th ed., Pearson Prentice Hall: New York; 2005; p 202. 